This item was submitted to Loughborough's Research Repository by the author.

Items in Figshare are protected by copyright, with all rights reserved, unless otherwise indicated.

\title{
Pseudo-vibration sensitivities for commercial laser vibrometers
}

PLEASE CITE THE PUBLISHED VERSION

http://dx.doi.org/10.1016/j.ymssp.2011.02.009

PUBLISHER

(c) Elsevier Ltd.

VERSION

AM (Accepted Manuscript)

LICENCE

CC BY-NC-ND 4.0

REPOSITORY RECORD

Martin, Peter, and Steve Rothberg. 2019. "Pseudo-vibration Sensitivities for Commercial Laser Vibrometers". figshare. https://hdl.handle.net/2134/8843. 
This item was submitted to Loughborough's Institutional Repository (https://dspace.lboro.ac.uk/) by the author and is made available under the following Creative Commons Licence conditions.

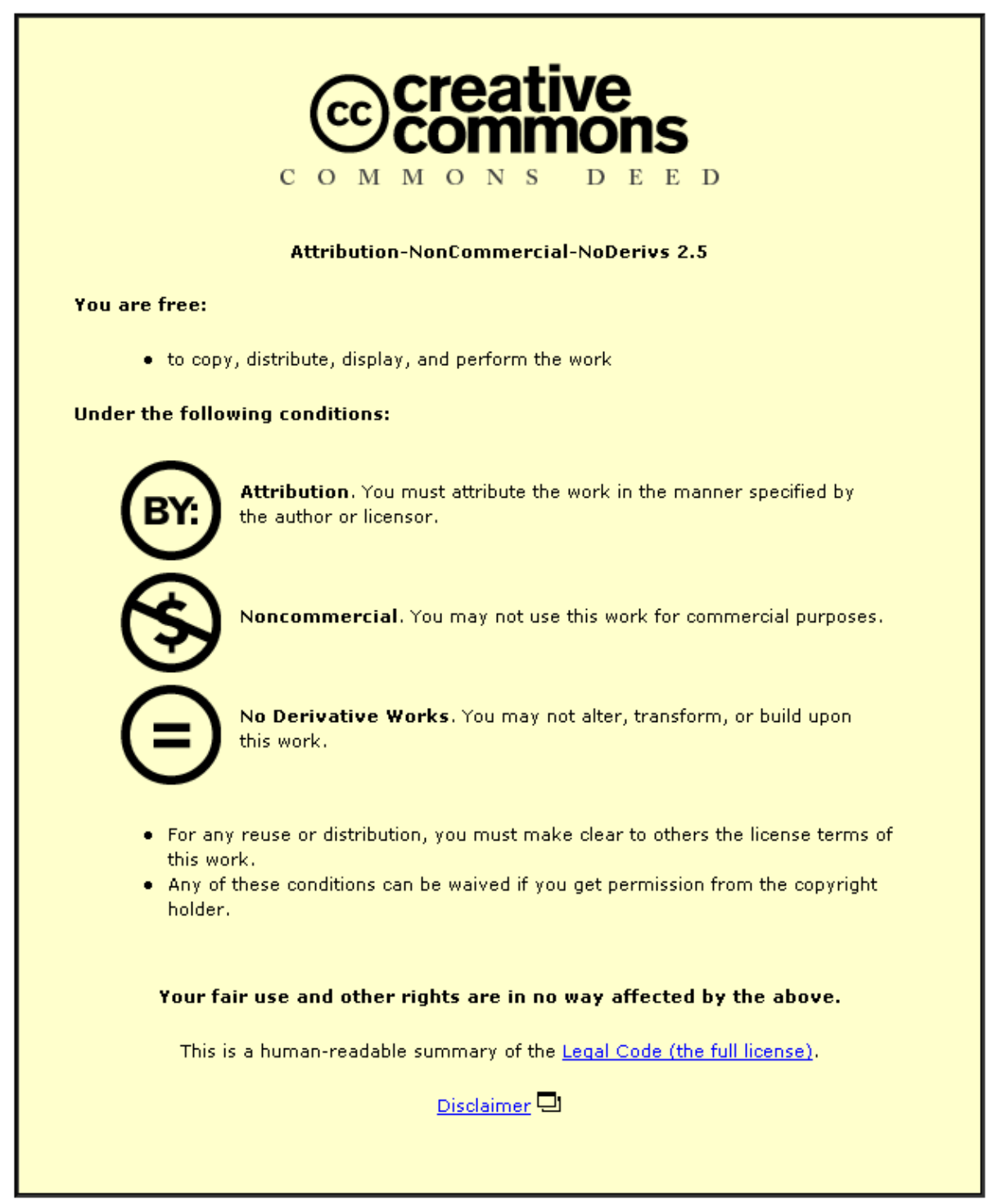

For the full text of this licence, please go to: http://creativecommons.org/licenses/by-nc-nd/2.5/ 


\section{Pseudo-Vibration Sensitivities for Commercial Laser Vibrometers}

Peter Martin and Steven J. Rothberg

Wolfson School of Mechanical and Manufacturing Engineering

Loughborough University, Loughborough, Leicestershire, LE11 3TU, UK.

Corresponding author: Steve Rothberg

e-mail: s.j.rothberg@lboro.ac.uk,

tel: +44 (0) 1509 227524,

fax: +44 (0) 1509227502 


\title{
Pseudo-Vibration Sensitivities for Commercial Laser Vibrometers
}

\author{
Peter Martin and Steve Rothberg \\ Wolfson School of Mechanical and Manufacturing Engineering, \\ Loughborough University, Loughborough, Leicestershire, LE11 3TU, UK.
}

e-mail: s.j.rothberg@lboro.ac.uk

\begin{abstract}
Pseudo-vibration sensitivities in laser vibrometry are the consequence of measurement noise generated by surface motions other than that on-axis with the incident laser beam(s), such as transverse and tilt vibrations or rotation. Concentrating solely on commercial laser vibrometers to maximise value to the vibrometer user, this paper quantifies pseudo-vibration sensitivities for five single beam instruments (for translational vibration measurement) and two parallel beam instruments (for angular vibration measurement) across a range of surface treatments and roughnesses. Transverse, tilt and rotation sensitivities are quantified for the single beam instruments. In-plane rotation, rotation, and tilt sensitivities are quantified for the parallel beam instruments. Estimates of sensitivities for parallel beam instruments based on related quantifications for single beam instruments are shown to offer order-of-magnitude agreement. Further confirmation is provided of the benefits of smaller laser beams for measurements on tilting or rotating surfaces and of larger beams for measurements on surfaces with transverse motion. For rotor vibration applications, lower sensitivities are found for a focus location on the shaft rotation axis rather than its surface. Based on experimental evidence, refinements to the test methods are suggested with a view towards the formation of a Standard. These comprise placing limits on surface flatness and rotor out-of-roundness, inclusion of agreed ranges for target displacement amplitude and rotor diameter, and acknowledgement of the importance of focus location for rotation sensitivities.
\end{abstract}

KEYWORDS: Laser vibrometry, speckle, pseudo-vibration, transverse sensitivity, tilt, rotation.

\section{Introduction}

The laser vibrometer is now established as an effective, non-contact alternative to the use of a traditional contacting vibration transducer such as the piezo-electric accelerometer. Laser vibrometers are technically well suited to general application but offer special benefits where certain measurement constraints are imposed, for example by the context, which may demand high frequency operation, high spatial resolution or remote transducer operation, or by the structure itself, which may be hot, 
light or rotating.

\subsection{Laser Speckle and Pseudo-Vibration}

A recognised drawback of the technique is the measurement noise caused by the formation of laser speckle [1] when vibration measurements are made on an optically rough surface. The laser vibrometer collects a portion of the backscattered speckle pattern and, when surface motion causes changes to the pattern, so-called 'speckle noise' is generated in the vibrometer output. The precise origins of this noise have been explained previously together with introduction of the term 'pseudovibration' $[2,3,4]$.

A 'fully-developed' speckle pattern is formed when a coherent laser beam, with a spot size in excess of any lateral scale to the surface roughness, scatters from a surface with roughness at least comparable with the optical wavelength (633 nm for all instruments in this paper). Surfaces with lower roughness are said to generate 'partially developed' speckle patterns in which a speckle pattern is observed in combination with an increasingly prominent specular (mirror-like) reflection. Retroreflective tape is a commonly used surface treatment in laser vibrometer measurements to maximise the return light intensity and also results in the formation of a speckle pattern. (In the experiments reported here, 3M Scotchlite High Gain Reflective Sheeting 7610 was used). Speckle noise is generated in measurements from all of these surfaces. Typical scattered light patterns from such a range of surfaces are shown in Fig. 1 in which it can also be seen that a larger incident beam diameter produces smaller speckles. Users of laser vibrometers may have observed such patterns on the front of the body of their vibrometer during use. In measurements on polished surfaces with Ra of the order of a few tens of nanometres, only specular reflections occur, as also shown in Fig. 1, but previous work [5] has revealed how noise still appears in the vibrometer output as a consequence of motion of the reflected light pattern across the vibrometer aperture. In this case, the term 'speckle noise' becomes inappropriate and so the more general term 'pseudo-vibration' is now used. The pseudo-vibration sensitivities reported in this paper cover this range of surface roughness, as well as surfaces treated with retro-reflective tape or painted.

The changes in collected light patterns causing pseudo-vibration are the consequence of surface motions other than the 'on-axis' motion (i.e. that directly along the line of the incident laser beam). Previous work, focussed on the development of methods for quantification of pseudo-vibration sensitivities [5], considered transverse motion (translational oscillation in a direction perpendicular to the laser beam direction), tilt motion (angular oscillation around an axis in a direction perpendicular to the laser beam direction) and rotation (continuous angular motion around an axis perpendicular to the laser beam direction). This paper builds on this initial work with first considerations of the effects of in-plane rotation (continuous angular motion around an axis parallel with the laser beam direction) and of angular vibration without rotation for a parallel beam instrument, as well as reporting pseudo- 
vibration sensitivities for a much wider range of commercial instruments. These data are offered as a valuable resource to vibrometer users who can apply the sensitivities presented for specific instruments and their applications. Furthermore, general conclusions are drawn to help reduce measurement noise in practice. This includes consideration for the first time of the beneficial effect, in measurements on a rotating shaft, of focussing the laser beam on the rotation axis rather than the shaft surface.

\subsection{Summary of Methods}

Inspired by the existence of a Standard for transverse sensitivity in accelerometers [6], methods for the quantification of pseudo-vibration sensitivities have recently been described in detail and validated [5]. A brief summary of these methods is provided here.

Dedicated test rigs are used to generate single component motions e.g. transverse vibration, angular (tilt) vibration or rotation with the aim, in each case, of minimising the genuine velocity along the line of the incident laser beam. This aim also requires precise alignment of the laser beam(s) which is included in the test procedures. Despite best efforts, however, genuine velocity components will be present in the measured velocity so these must be compensated for by additional measurements. Two methods have been developed to make this compensation. In method A, an independent, simultaneous measurement of genuine velocity is made and subtracted from the velocity measured by the laser vibrometer to produce an apparent velocity, dominated by noise. Method B was developed for situations where the measurement of genuine velocity could not be obtained, although it is now regarded as a perfectly reasonable alternative even when this measurement can be obtained. Two laser vibrometer measurements are made simultaneously using identical instruments. The laser beams have identical alignment and are positioned as close together as possible without overlap. Subtraction of their outputs is intended to cancel common components such as genuine vibration and, for rotor measurements on smoother surfaces, shaft out-of-roundness, leaving only uncorrelated noise components. As a result of the subtraction, the resulting signal takes a rms level that is $\sqrt{2}$ times either of the individual rms levels. Scaling then produces the apparent velocity, dominated by noise. Pseudovibration sensitivities are calculated from these apparent velocities and the particular method used is indicated in the data tables presented. All measurements were taken at one of the specific manufacturer's recommended stand-off distances and these are provided in Appendix A.

Fundamental to the quantification is the observation that the noise generated is pseudo-random; when noise is generated in a measurement from a surface vibrating at a single frequency or rotating at a fixed speed, spectral peaks of pseudo-vibration will appear not only at the same frequency as this vibration or rotation but also at many harmonics of it, as shown in Fig. 2. The figure shows how amplitudes are maintained across many harmonics and how the highest levels are not necessarily found at the lowest harmonics. Based on the formation of such spectra from independent 
measurements, pseudo-vibration is quantified as a map, showing the mean and standard deviation of each order in the range from 1 to 50, and an example of this is shown in Fig. 3 for the Polytec PDV100 laser vibrometer and surface roughnesses Ra $1.0 \mu \mathrm{m}$ and Ra $11 \mathrm{~nm}$. From the map, a mean level per order across 10 orders (with standard deviation) and a total RMS across 10 orders are also calculated to facilitate comparisons between instruments and measurement scenarios. The first ten orders are used for these calculations except for rotation sensitivities where the first twenty orders can be affected by shaft out-of-roundness in tests on smoother surfaces and by components of genuine velocity generated by the need to rotate the shaft. For such cases, orders 21-30 are used, relying on the flat spectral shape of the noise generated. The levels on the map are normalised either by the amplitude of the sinusoidal transverse or tilt velocity of the test surface or by the rotation angular frequency of the test shaft using independent measurements.

In one set of measurements (Brüel \& Kjær 2523 in Table 5), a correction measurement could not be arranged and an identical instrument was not available to make the differential measurement. These measurements are noted in data tables as method $A^{*}$ in which the use of orders 21-30 is the only step available to try to ensure apparent velocity is dominated by pseudo-vibration.

Sensitivities for single beam instruments, which measure translational vibrations, are presented in section 2. This includes the Polytec OFV400 instrument which is a parallel beam instrument with a simple cap that enables operation in a single beam mode. Parallel beam instruments, which measure angular vibrations, are the subject of section 3. General trends can equally be observed in the mean levels per order or in the total rms levels. The discussion presented is structured around the mean levels per order with their associated standard deviations but it is conducted in round number terms. Full details are provided for the vibrometer user in the Tables.

The experience gained in this study has highlighted a number of important factors for consideration in the refinement of the methods, with the ultimate intention of formulating a dedicated Standard for pseudo-vibration sensitivities. For transverse and tilt sensitivities, a key issue is the choice of vibration amplitude and this matter is explored in detail in this paper using experimental evidence.

\section{Pseudo-Vibration Sensitivities: single beam instruments}

\subsection{Transverse Sensitivity}

Fig. 4 shows the test set-up used for the transverse sensitivity quantification using method A. A surface vibration displacement of $420 \mu \mathrm{m}$ rms was used in these tests to reflect vibration amplitudes found in practice and because it corresponded to a translation of at least one whole beam diameter for the largest beam. Transverse sensitivities are given in Tables $1 \mathrm{a} \& \mathrm{~b}$ which show data for 4 different instruments using the two different methods. 
For each instrument, transverse sensitivities vary little for the surfaces generating speckle patterns with mean levels around $0.03 \%$ for small beams down to $0.01 \%$ for larger beams. The standard deviations associated with the mean levels per order are generally in the range of a half to two-thirds of their corresponding mean value. This effect of beam diameter might have been anticipated from laser speckle intensity statistics which, for a given surface displacement, predict increased speckle pattern correlation times with increasing beam diameter [7, 8]. The same effect was also articulated in terms of frequency broadening of the photodetector output due to the finite transit time of particles moving through the illuminating beam, at an early stage in the development of laser Doppler techniques [9]. From the Ra $11 \mathrm{~nm}$ surface generating a specular reflection, the sensitivities for smaller beams are much lower, by factors of more than ten for the OFV505 and PDV100 instruments, but this may be a consequence of the method used as discussed later in section 4.1.

\subsection{Tilt Sensitivity}

Fig. 5 shows the test surface used for the tilt sensitivity quantification. An angular displacement of at least $0.5^{\mathrm{O}} \mathrm{rms}$ was used in these tests to reflect realistic vibration amplitudes while ensuring a translation of any collected speckle by at least one whole photodetector width. This latter condition is easily met and associated speckle translation distances are much greater than the photodetector dimensions. The beam is incident directly on the rotation axis of the tilting surface, with care taken to minimise any offset, $y_{0}$, from this position. For method A, a separate measurement of genuine on-axis velocity is taken from the bearing housing in which the carriage is supported. Tilt sensitivities are given in Tables $2 \mathrm{a} \& \mathrm{~b}$ which show data for 4 different instruments.

Tilt sensitivities are similar for all surfaces for any one instrument. Sensitivities are also very similar for the 3 instruments with smaller beams at a mean level per order around $0.07 \mu \mathrm{m} \mathrm{s}^{-1} / \mathrm{deg} \mathrm{s}^{-1}$. This increases by a factor of almost 4 for the instrument with the larger beam. Standard deviations are in the range of 0.5 to 0.9 of their corresponding mean value. The effect of beam diameter in measurements from the rougher surfaces might have been anticipated from laser speckle statistics which, for a given surface angular displacement, predict increased speckle pattern correlation times with decreasing beam diameter as a result of increasing speckle size [10, 11]. This same effect of beam diameter was recognised at an early stage in the development of laser Doppler techniques [9] and articulated as 'velocity gradient broadenings' which refers to changes in the direction of each particle's velocity vector (and therefore to its associated Doppler shift) as it passes through an illuminated region of finite size.

\subsection{Rotation Sensitivity (radial vibration)}

Fig. 6 shows the test surface used for the rotation sensitivity quantification, with 2 beams incident in the manner required for method $\mathrm{B}$. The beams are arranged to pass through and be perpendicular to 
the axis of rotation as is required for measurement of radial vibration [12]. Rotation sensitivities, based on orders 21-30, are given in Tables 3a\&b which show data for 5 different instruments.

Rotation sensitivities generally increase with increasing beam diameter. For the three instruments with beam diameters below $100 \mu \mathrm{m}$, sensitivities vary little across the surfaces producing speckle patterns with a mean level per order around $0.5 \mu \mathrm{m} \mathrm{s}^{-1} / \mathrm{rad} \mathrm{s}^{-1}$ and standard deviations around 0.5 to 0.9 of their corresponding mean value. For these surfaces and larger beams, levels are 2 to 3 times higher with the highest sensitivities seen for the surface with retro-reflective tape. The effect of beam diameter in measurements from these surfaces might be anticipated from laser speckle statistics [13] which predict similar effects of beam diameter to those found for the case of surface tilt. Sensitivities reduce significantly in the absence of a speckle pattern; between Ra $65 \mathrm{~nm}$ and Ra $11 \mathrm{~nm}$, the 4 Polytec instruments show a fourfold decrease in rotation sensitivity while the Ometron instrument shows a reduction by a factor slightly less than 2 . The 4 Polytec instruments cover a beam diameter range from $45 \mu \mathrm{m}$ to $520 \mu \mathrm{m}$ but the sensitivities from the Ra $11 \mathrm{~nm}$ measurements are all very similar.

\subsubsection{Effect of shaft diameter and location of focus}

The rotation sensitivities given in Tables $3 \mathrm{a} \& \mathrm{~b}$ are from a target shaft with a diameter of $15 \mathrm{~mm}$ and a laser beam focussed on the shaft surface. Table $3 \mathrm{c}$ shows the effect on the rotation sensitivity of shaft diameter, using shafts of diameter $15 \mathrm{~mm}, 40 \mathrm{~mm}$ and $110 \mathrm{~mm}$, each treated with retro-reflective tape (beam diameter $90 \mu \mathrm{m}$ ). Rotation sensitivities are presented for a beam focussed on the shaft rotation axis (as close as is practically possible) as well as on the shaft surface.

There is a clear and statistically significant increase in mean level per order in the progression from 15 $\mathrm{mm}$ to $40 \mathrm{~mm}$ to $110 \mathrm{~mm}$ diameter for the measurements with beams focussed on the shaft surface. Within the range considered, this increase suggests sensitivities are approximately proportional to the square root of shaft diameter. For the smallest shaft, of $15 \mathrm{~mm}$ diameter, there is negligible difference between sensitivities for focus location on the shaft surface or on its rotation axis. Considerable reductions are, however, achieved for the $40 \mathrm{~mm}$ and $110 \mathrm{~mm}$ diameter shafts by focussing on the rotation axis of the shaft rather than its surface. These sensitivities and that for the smallest shaft (focus at the surface) are noticeably similar. Between the smallest shaft and the $40 \mathrm{~mm}$ diameter shaft with focus on the rotation axis, there is no statistically significant difference. Between the smallest shaft and the $110 \mathrm{~mm}$ diameter shaft with focus on the rotation axis, there is a statistically significant difference but it is now only marginal at the $95 \%$ level of confidence according to Tukey's test. These observations strongly suggest that the lowest rotation sensitivities (with values possibly independent of shaft diameter) can be obtained by focus on a shaft rotation axis rather than its surface. This has a significant practical implication. For example, in a measurement on a shaft with diameter around 100 $\mathrm{mm}$ (rough surface or surface coated in retro-reflective tape), choice of an instrument with a small 
beam diameter and focus on the shaft rotation axis might result in five times less noise than choice of an instrument with a large beam diameter and focus on the shaft surface.

\section{Pseudo-Vibration Sensitivities: parallel beam instruments}

\subsection{In-plane Rotation Sensitivity}

Fig. 7 shows the test set-up used for this quantification. Two pairs of beams are incident in the manner required for method $\mathrm{B}$ with the plane of each pair of beams arranged to be parallel to the axis of rotation as is required for measurement of pitch or yaw vibration with maximum sensitivity [14]. In this part of the study, 2 surface treatments - retro-reflective tape and white paint - were considered rather than surface roughness. The OFV400 was the only instrument available that was capable of this measurement. In-plane rotation sensitivity as a mean level per order takes a value around $1.5 \mathrm{mdeg} \mathrm{s}^{-1}$ $/ \mathrm{rad} \mathrm{s}^{-1}$ with a standard deviation around half this value. Measurements using retro-reflective tape demonstrate levels about 20\% lower than those from the painted surface, as shown in Table 4.

\subsection{Rotation Sensitivity (torsional vibration)}

Fig. 8 shows the test set-up used for this quantification in which the plane of each pair of beams is arranged to be perpendicular to the axis of rotation as is required for measurement of torsional vibration with maximum sensitivity [14]. Two pairs of beams are incident in the manner required for method B. Rotation sensitivities for 2 different instruments, including data for a range of stand-off distances for the Brüel \& Kjær 2523 instrument, are given in Table 5. Low collected light intensity results when a laser beam is incident at a location on an untreated surface where the surface normal is significantly different from the direction of laser beam incidence. In this set of tests, this prevented reliable measurements unless retro-reflective was applied to the surface.

For the Brüel \& Kjær 2523, there would appear to be an optimum stand-off distance in the region of $200 \mathrm{~mm}$ with regard to rotation sensitivity. Beyond this, rotation sensitivity increases with increasing beam diameter as encountered elsewhere in similar measurements. With a mean level per order of approximately $20 \mathrm{mdeg} \mathrm{s}^{-1} / \mathrm{rad} \mathrm{s}^{-1}$, the lowest rotation sensitivity is found with the Polytec OFV400. An analysis based on orders 1-10 is also shown in Table 5. Broadly similar values are seen because measurements on rough surfaces, including those treated with retro-reflective tape, are insensitive to shaft out-of-roundness [12].

\subsection{Tilt Sensitivity}

The test set-up uses the same test rig from the tilt sensitivity quantification for a single beam instrument, as shown in Fig. 10. Here, two pairs of beams are incident on the target surface in the manner required for method $\mathrm{B}$. The plane of each pair of beams is arranged to be perpendicular to the axis of rotation as is required for measurement of angular vibration around the $z$-axis with maximum sensitivity. The OFV400 is the only instrument available that is capable of this measurement. The 
instrument set-up is quite similar to that used in section 3.2 for rotation sensitivity in a torsional vibration measurement. The difference here is that the target has an angular oscillation around the $z$ axis rather than a continuous rotation. This makes this last pseudo-vibration quantification subtly different from all others presented in this paper in that it quantifies the pseudo-vibration sensitivity to the very same motion that it is intended to measure.

The results show a clear advantage to the use of retro-reflective for this application, even over the polished surface; tilt sensitivity of around $0.2 \%$ per order (standard deviation of around half this level) is approximately half the level for the Ra $1 \mu \mathrm{m}$ surface and a quarter of that encountered for the smooth Ra $11 \mathrm{~nm}$ surface. The tilt motion produces a spread of Doppler shifts across each beam in a pair and the high sensitivity in the measurement from the smoothest surface is likely to be due to continuous changes in the region of the incident beam from which light is collected during the measurement.

\subsection{Estimating sensitivities for parallel beam instruments based on single beam instrument} sensitivities

Parallel beam measurements (of angular vibration) can be regarded as differential (translational vibration) measurements using two single beams. Estimate of pseudo-vibration sensitivities for parallel beam instruments is therefore possible based on the corresponding sensitivities for single beam instruments. This is not recommended as a means of quantification but should be useful as an approximate method in the absence of measured data. To convert from two translational vibration measurements to the angular vibration measurement requires subtraction of the two translational velocities and division by their perpendicular separation. In terms of noise levels, subtraction results in a noise level whose rms is $\sqrt{2}$ times either of the individual rms levels while division by the perpendicular beam separation, $d$, simply scales the sensitivity and provides appropriate angular velocity units. If the sensitivity (mean level per order across orders $N 1$ to $N 2$ ) from the single beam instrument is $\left(\overline{\mathrm{S}_{\mathrm{PV}, \mathrm{N} 1 \rightarrow \mathrm{N} 2}}\right)_{1}$ then the corresponding estimated sensitivity for the parallel beam instrument, $\left[\left(\overline{S_{P V, N 1 \rightarrow N 2}}\right)_{2}\right]_{e s t}$, is given by:

$\left[\left(\overline{S_{P V, N 1 \rightarrow N 2}}\right)_{2}\right]_{e s t}=s \frac{\sqrt{2}}{d}\left(\overline{S_{P V, N 1 \rightarrow N 2}}\right)_{1}$

where $s$ is a scaling factor to convert from the units of $\left(\overline{S_{P V, N 1 \rightarrow N 2}}\right)_{1} / d$ to the desired units for $\left(\overline{S_{P V, N 1 \rightarrow N 2}}\right)_{2}$ including any change in normalisation, for example from vibration amplitude to rotation speed. Example calculations follow for the Polytec OFV400 instrument, which has $8 \mathrm{~mm}$ beam separation when used as a parallel beam instrument but which has also been used in a single beam mode. 
In section 3.1, in-plane rotation sensitivities, associated with pitch or yaw vibration measurements made on the face of a shaft, were presented. The closest single beam measurement scenario is the transverse sensitivity quantification although the motion in a circular arc of a surface point as it passes through the beam does affect the speckle behaviour [15]. Taking data for retro-reflective tape from Table 1a, $\left(\overline{S_{P V, 1 \rightarrow 10}}\right)_{1}=0.0112 \%$ and

$\left[\left(\overline{S_{P V, 1 \rightarrow 10}}\right)_{2}\right]_{e s t}=\left(\frac{1}{100} \frac{0.5 d \omega}{\omega} \frac{3601000}{2 \pi}\right) \frac{\sqrt{2}}{d}\left(\overline{S_{P V, 1 \rightarrow 10}}\right)_{1}=4.54 \mathrm{mdeg} \mathrm{s}^{-1} / \mathrm{rad} \mathrm{s}^{-1}$.

where $\omega$ is the shaft rotation angular velocity. Equation (2) shows how the scaling factor removes the effect of expressing the sensitivity as a percentage, multiplies by transverse surface velocity, normalises by rotation speed and converts from rad to mdeg. From Table $4,\left(\overline{S_{P V, 21 \rightarrow 30}}\right)_{2}=1.28$ mdeg $\mathrm{s}^{-1} / \mathrm{rad} \mathrm{s}^{-1}$. Taking into account standard deviations, the ranges covered by the mean plus/minus one standard deviation do overlap for the estimated data and the measured data but the estimated mean value is clearly quite high.

Pitch and yaw vibration measurements can also be made by aligning the beams axially along the length of the shaft, rather than on its face, such that each beam passes perpendicularly through the rotation axis [14] with an axial separation of the beams equal to the perpendicular beam separation. This measurement has not been made but the arrangement is the parallel beam equivalent of the single beam vibration measurements described in section 2.3 , with the similarity much greater than for the transverse motion example above. Taking data for retro-reflective tape from Table 3a, $\left(\overline{S_{P V, 21 \rightarrow 30}}\right)_{1}=1.68 \mu \mathrm{m} \mathrm{s}^{-1} / \mathrm{rad} \mathrm{s}^{-1}$ and the corresponding sensitivity in a pitch or yaw measurement from the side of a shaft is given by:

$\left[\left(\overline{S_{P V, 21 \rightarrow 30}}\right)_{2}\right]_{e s t}=\left(\frac{360}{10002 \pi}\right) \frac{\sqrt{2}}{d}\left(\overline{S_{P V, 21 \rightarrow 30}}\right)_{1}=17.0 \mathrm{mdeg} \mathrm{s}^{-1} / \mathrm{rad} \mathrm{s}^{-1}$

where the scaling factor makes the necessary conversion from $\mu \mathrm{rad}$ to mdeg. Compared to a sensitivity of only $1.28 \mathrm{mdeg} \mathrm{s}^{-1} / \mathrm{rad} \mathrm{s}^{-1}$ for measurement from the face of the shaft, this suggests a significant noise advantage to measurement from the face of a shaft rather than along its side for the pitch / yaw vibration measurement.

Rotation sensitivity (torsional vibration) can also be estimated based on the rotation sensitivity (radial vibration). The prediction of this rotation sensitivity is identical to the calculation in equation (3) giving a mean level per order of $\left[\left(\overline{S_{P V, 21 \rightarrow 30}}\right)_{2}\right]_{e s t}=17.0 \mathrm{mdeg} \mathrm{s}^{-1} / \mathrm{rad} \mathrm{s}^{-1}$. Despite differences in location of the incident beams around the shaft, this estimate compares well with the measured values of $16.1 \mathrm{mdeg} \mathrm{s}^{-1} / \mathrm{rad} \mathrm{s}^{-1}$ (from orders 1-10) and $21.5 \mathrm{mdeg} \mathrm{s}^{-1} / \mathrm{rad} \mathrm{s}^{-1}$ (from orders 21-30), as shown in Table 5. 
Similarly, tilt sensitivity of a parallel beam instrument can be based on its single beam counterpart. Taking data for retro-reflective tape from Table $2 \mathrm{a},\left(\overline{S_{P V, 1 \rightarrow 10}}\right)_{1}=0.279 \mu \mathrm{m} \mathrm{s}^{-1} / \mathrm{deg} \mathrm{s}^{-1}$ and:

$\left[\left(\overline{S_{P V, 1 \rightarrow 10}}\right)_{2}\right]_{e s t}=\left(\frac{360}{1 e 62 \pi} 100\right) \frac{\sqrt{2}}{d}\left(\overline{S_{P V, 1 \rightarrow 10}}\right)_{1}=0.282 \%$

where the scaling factor converts from $\mu \mathrm{rad}$. to deg. and then to percentage. This sits within the range between mean and mean plus one standard deviation from the full quantification while estimates for the $\mathrm{Ra} 1 \mu \mathrm{m}$ and $\mathrm{Ra} 11 \mathrm{~nm}$ surfaces sit in the range between mean and mean minus one standard deviation. The trend through the different surfaces, however, is not replicated in the estimates which are based on a measurement aligned through the rotation axis rather than an arrangement where both beams are offset from the rotation axis. Whilst there is clearly still value in estimating parallel beam sensitivities based on single beam sensitivities, these cases emphasise the need for full quantifications to be made when reliable pseudo-vibration sensitivities are required.

\section{Towards a Standard for Pseudo-Vibration Sensitivity}

A number of factors have emerged during the course of this study which appear to influence measured sensitivities. These are reviewed in this section in the context of the formulation of a Standard for evaluation of pseudo-vibration sensitivities.

\subsection{Surface Flatness}

In transverse sensitivity measurements on the smoothest surface, vibrometer outputs were sometimes affected by spikes due to signal dropouts (loss of signal due to insufficient collected light intensity). The authors believe that these were the result of local variations in flatness on the test surfaces. Wherever such problems were encountered, adjustments to the location of the illuminating beam were made until the problem was eliminated or, at least, minimised. Particularly for a tightly focussed beam, individual wavelets away from the centre of beam are incident along a line that makes an angle of less than $90^{\circ}$ to the direction of surface motion, resulting in Doppler shifts. When the collected light sits centrally over the aperture, these shifts are balanced by the symmetry of the beam. When a polished surface is not flat, however, the light collected is seen to move back and forth across the aperture in sympathy with the transverse surface motion and these shifts from the outer regions of the beam are no longer balanced by its symmetry such that a time-varying component of the transverse surface velocity appears in the measurement. If the mechanism proposed is true then a general trend of increasing sensitivity with tighter focus (i.e. generally smaller beam diameter) would be expected. This appears to be the case in comparisons between the two instruments with beam diameters of 45 $\mu \mathrm{m}$ and $60 \mu \mathrm{m}$ and between the two instruments with beam diameters of $90 \mu \mathrm{m}$ and $520 \mu \mathrm{m}$ but the large increase apparent between the sensitivities for the instruments with $60 \mu \mathrm{m}$ and $90 \mu \mathrm{m}$ beam diameters would appear to be driven by another mechanism. Measured transverse sensitivities (on 
polished surfaces) may well depend on the method used. Method A is expected to be most affected because method B, with its two closely spaced measurements, should provide a degree of cancellation. In Table 1a, for the Ra $11 \mathrm{~nm}$ surface, it is noticeable that transverse sensitivities quantified by method B are very significantly lower than transverse sensitivities quantified by method

A. The measurement under method A more closely resembles a 'normal' measurement and so method A sensitivities may be more reliable for polished surfaces. It may also be necessary to impose a limit on flatness in the refinement of test methods.

\subsection{Effect of vibration displacement amplitude}

The choice of vibration amplitude has emerged as an important factor in quantifying pseudo-vibration sensitivities. The transverse and angular displacements chosen ensured a decorrelation of the speckle pattern incident on the collecting aperture of the laser vibrometer through a vibration cycle. For transverse motions, further tests were performed in which vibration displacement was halved 3 times over i.e. $210 \mu \mathrm{m} \mathrm{rms}, 105 \mu \mathrm{m}$ rms and $52.5 \mu \mathrm{m}$ rms. Fig. 10 shows three transverse sensitivity maps (standard deviations omitted for clarity) from measurements on a surface with Ra $1.0 \mu \mathrm{m}$. For vibration displacements $420 \mu \mathrm{m}$ rms and $52.5 \mu \mathrm{m}$ rms (equivalent to 4.67D and 0.56D for beam diameter $\mathrm{D}=90 \mu \mathrm{m}$ ), the figure shows similar levels overall but a change in the spectral shape with increased sensitivities at low orders and decreased sensitivities at higher orders for the smaller displacement. For comparison, Fig. 10 also shows the transverse sensitivity map for a $520 \mu \mathrm{m}$ beam diameter and $420 \mu \mathrm{m} \mathrm{rms} \mathrm{displacement} \mathrm{(equivalent} \mathrm{to} \mathrm{0.81D} \mathrm{for} \mathrm{this} \mathrm{larger} \mathrm{beam} \mathrm{diameter);} \mathrm{in} \mathrm{terms}$ of the ratio of displacement to beam diameter, this case (ratio 0.81) can be compared to the $52.5 \mu \mathrm{m}$ rms displacement with beam diameter $90 \mu \mathrm{m}$ (ratio 0.56). The sensitivities differ but the similarity in spectral shape between these two maps is quite clear.

The effect of vibration amplitude is demonstrated further in Table 7 which shows the progression in transverse sensitivity across the 4 vibration amplitudes for the Polytec OFV302 instrument. The mean level per order, based on the first ten orders, increases by a factor of 1.8 with an eight-fold reduction in vibration amplitude while the standard deviations remain fixed at around two-thirds of their corresponding means. Further analysis using Tukey's test shows that the statistically significant differences lie between the transverse sensitivity for $52.5 \mu \mathrm{m}$ rms displacement and $420 \mu \mathrm{m} \mathrm{rms}$ displacement, and $52.5 \mu \mathrm{m}$ rms displacement and $210 \mu \mathrm{m} \mathrm{rms} \mathrm{displacement.} \mathrm{This} \mathrm{suggests} \mathrm{that}$ transverse sensitivities based on surface displacements comparable with or greater than beam diameter may underestimate the transverse sensitivities associated with much lower displacements by as much as a factor of two. Inclusion of displacement amplitude data in the quantification of pseudovibration sensitivities is clearly necessary. Definition of an agreed amplitude or range of amplitudes at which to make quantification(s) is necessary in developing these test methods as a Standard.

\subsection{Shaft Out-of-Roundness}


The rotation sensitivity (radial vibration) for the Ra $65 \mathrm{~nm}$ surface with the OFV505, which has the smallest beam diameter, bucks the normal trend and appears larger than the sensitivities from other surfaces with this instrument, as shown in Tables $3 \mathrm{a} \& \mathrm{~b}$. Sourcing the tests shafts with their different roughness values was difficult and it was not possible to maintain control simultaneously over out-ofroundness which happened to be much larger for this shaft than for others ( $27 \mu \mathrm{m}$ compared to others in the range of 1-7 $\mu \mathrm{m})$. It is the authors' view that out-of-roundness is responsible for the anomalously high level, despite use of orders 21-30, and any future Standard should include a limit on out-of-roundness, perhaps of the order of $10 \mu \mathrm{m}$.

\subsection{Shaft Diameter and Location of Focus}

In section 2.3.1, the dependence of rotation sensitivity on shaft diameter was described as well as the beneficial effect (for larger diameters) of focusing the probe beam on the rotation axis rather than on the rotor surface. While the advantage of focussing on the rotation axis is clear, not all commercial laser vibrometers allow focussing and so a Standard should allow for either possibility. A shaft diameter or range of diameters must be agreed and embodied in the Standard.

\subsection{Stand-off distance}

Manufacturers' recommended stand-off distances were used in all experimentation but, for any one instrument, there is either more than one recommended stand-off distance or a recommended distance range. In section 3.2 and Table 5, stand-off distance was shown to affect the measured sensitivity for the Brüel \& Kjær 2523 instrument. The trend observed cannot be readily applied to other instruments but the data serve to highlight that this is an additional factor in need of definition.

\section{Conclusions}

This paper has presented, for the first time, a comprehensive set of pseudo-vibration sensitivities for a range of commercial laser vibrometers. The sensitivities have covered a variety of surface motion types, a range of surface roughnesses and treatments and both single beam and parallel beam laser vibrometers. Two main methods have been used; method B is based on a differential measurement and has emerged as the preferred method for ease of application and reliability of outcome while method A, which requires acquisition of an independent correction measurement, has also proved successful. In a simplified version of method A, sensitivities have also been quantified in the absence of a correction measurement based on the use of higher orders (method $\mathrm{A}^{*}$ ) but this is regarded as the least reliable approach. The ability to calculate pseudo-vibration sensitivities for parallel beam measurements based on similar single beam measurements has also been demonstrated and shown to be useful but only in making order-of-magnitude estimates rather than as an alternative to a proper quantification. The importance of focus location in measurements on rotors has also been demonstrated for the first time. Focus on the shaft surface results in sensitivities that are roughly 
proportional the square root of shaft diameter. Focus on the rotation axis, however, results in minimised rotation sensitivities that appear largely independent of shaft diameter. The study has pointed the way towards formulation of a Standard, having drawn out key issues such as the range of motion types, displacement amplitudes, stand-off distances, flatness and, for rotation sensitivities, shaft diameter, out-of-roundness and focus location. The data presented are immediately useful to laser vibrometer users, enabling improved data interpretation wherever pseudo-vibrations occur.

\section{Acknowledgements}

The authors would like to acknowledge the support of the Engineering and Physical Sciences Research Council, who funded this project, the Royal Commission for the Exhibition of 1851, who funded essential equipment purchase, and Polytec for the loan of PDV100 and OFV505 laser vibrometers.

\section{References}

[1] Goodman J W, Some fundamental properties of speckle. Journal of the Optical Society of America 66(11) (1976) 1145-1150.

[2] S.J. Rothberg, J.R. Baker and N.A. Halliwell, Laser vibrometry: Pseudo-vibrations. Journal of Sound and Vibration 135(3) (1989) 516-522.

[3] S.J. Rothberg, Numerical simulation of speckle noise in laser vibrometry. Applied Optics 4519 (2006) 4523-4533.

[4] P. Martin and S.J. Rothberg, Introducing speckle noise maps for laser vibrometry. Optics and Lasers in Engineering 47(3-4) (2009) 431-442.

[5] P. Martin and S.J. Rothberg, Methods for the quantification of pseudo-vibration sensitivities in laser vibrometry. accepted by Measurement Science and Technology (2010).

[6] International Organization for Standardization ISO 16063-31 Methods for the calibration of vibration and shock transducers: Testing of transverse vibration sensitivity, 2009.

[7] T. Asakura and N. Takai, Dynamic laser speckles and their application to velocity measurements of the diffuse object. Applied Physics 25 (1981) 179-194.

[8] I.D.C. Tullis, N.A. Halliwell and S.J. Rothberg, Spatially integrated speckle intensity: maximum resistance to decorrelation caused by in-plane target displacement. Applied Optics 37(30) (1998) 7062-7069.

[9] L.E. Drain, The Laser Doppler Technique, Wiley, London, 1980.

[10] I. Yamaguchi I and T. Fujita, Laser speckle rotary encoder. Applied Optics 28(20) (1989) 4401-4406.

[11] I.D.C. Tullis, N.A. Halliwell and S.J. Rothberg, Shaft tilt sensitivity of the laser torquemeter, Proceedings of the 3rd International Conference on Vibration Measurements by Laser Techniques, SPIE Vol. 3411 Ancona, Italy, 1998, pp. 309-316. 
[12] J.R. Bell and S.J. Rothberg, Laser vibrometers and contacting transducers, target rotation and 6 degree-of-freedom vibration: What do we really measure? Journal of Sound and Vibration 237(2) (2000) 245-61.

[13] N. Takai, T. Iwai and T. Asakura, An effect of curvature of rotating diffuse objects on the dynamics of speckles produced in the diffraction field. Applied Physics B 26 (1981) 185-192.

[14] J.R. Bell and S.J. Rothberg, Rotational vibration measurements using laser Doppler vibrometry: Comprehensive theory and practical applications. Journal of Sound and Vibration 238(4) (2000) 673-690.

[15] J.H. Churnside, Speckle from a rotating diffuse object. Journal of the Optical Society of America 72(11) (1982) 1464-1469. 


\section{Figure Captions}

Figure 1. Typical scattered light patterns

Figure 2. Typical spectrum of apparent velocity dominated by speckle noise.

Figure 3. Transverse sensitivity map for Polytec PDV100. Method B.

Figure 4. Test set-up for quantification of transverse sensitivity. Method A.

Figure 5. Test set-up for quantification of tilt sensitivity. Method A.

Figure 6. Test set-up for quantification of rotation sensitivity (radial vibration). Method B.

Figure 7. Test set-up for quantification of parallel beam in-plane rotation sensitivity (pitch / yaw vibration). Method B.

Figure 8. Test set-up for quantification of parallel beam rotation sensitivity (torsional vibration). Method B.

Figure 9. Test set-up for quantification of parallel beam tilt sensitivity. Method B.

Figure 10. Effect of vibration amplitude on transverse sensitivity. Surface Ra $1.0 \mu \mathrm{m}$ 


\section{Table Captions}

Table 1a. Transverse sensitivity (\%) per order: mean (standard deviation) over orders 1-10. Target displacement $420 \mu \mathrm{m}$ rms.

Table 1b. Transverse sensitivity (\%): Total rms across orders 1-10. Target displacement $420 \mu \mathrm{m} \mathrm{rms}$.

Table 2a. Tilt sensitivity $\left(\mu \mathrm{m} / \mathrm{s}^{-1} / \operatorname{deg~s} \mathrm{s}^{-1}\right)$ per order: mean (standard deviation) over orders 1-10. Angular displacement $0.78^{\circ} \mathrm{rms}$.

Table 2b. Tilt sensitivity $\left(\mu \mathrm{m} \mathrm{s}^{-1} / \operatorname{deg~s}^{-1}\right)$ : Total rms over orders 1-10. Angular displacement $0.78^{\circ}$ rms.

Table 3a. Rotation sensitivity (radial vibration, $\mu \mathrm{m} \mathrm{s}^{-1} / \mathrm{rad} \mathrm{s}^{-1}$ ) per order: mean (standard deviation) over orders 21-30. Shaft diameter $15 \mathrm{~mm}$.

Table 3b. Rotation sensitivity (radial vibration, $\mu \mathrm{m} \mathrm{s}^{-1} / \mathrm{rad} \mathrm{s}^{-1}$ ): Total $\mathrm{rms}$ over orders 21-30. Shaft diameter $15 \mathrm{~mm}$.

Table 3c. Rotation sensitivity (radial vibration, $\mu \mathrm{m} \mathrm{s}^{-1} / \mathrm{rad} \mathrm{s}^{-1}$ ) per order as a function of shaft diameter and focus location: mean (standard deviation) over orders 21-30. Surfaces treated with retroreflective tape. Beam diameter $90 \mu \mathrm{m}$. Method B, Polytec OFV302/323.

Table 4. Parallel beam, in-plane rotation sensitivity (pitch / yaw vibration, $\mathrm{mdeg} \mathrm{s}^{-1} / \mathrm{rad} \mathrm{s}^{-1}$ ) over orders 21-30. Shaft diameter $15 \mathrm{~mm}$.

Table 5. Parallel beam rotation sensitivity (torsional vibration, $\mathrm{mdeg} \mathrm{s}^{-1} / \mathrm{rad} \mathrm{s}^{-1}$ ) over orders 21-30 (over orders 1-10). Surface coated in retro-reflective tape. Shaft diameter $15 \mathrm{~mm}$.

Table 6. Parallel beam tilt sensitivity (\%) over orders 1-10. Angular displacement $0.78^{\circ} \mathrm{rms}$.

Table 7. Transverse sensitivity (\%) over orders 1-10 as a function of displacement amplitude. Beam diameter $90 \mu \mathrm{m}$, surface Ra $1.0 \mu \mathrm{m}$. Polytec OFV302. 


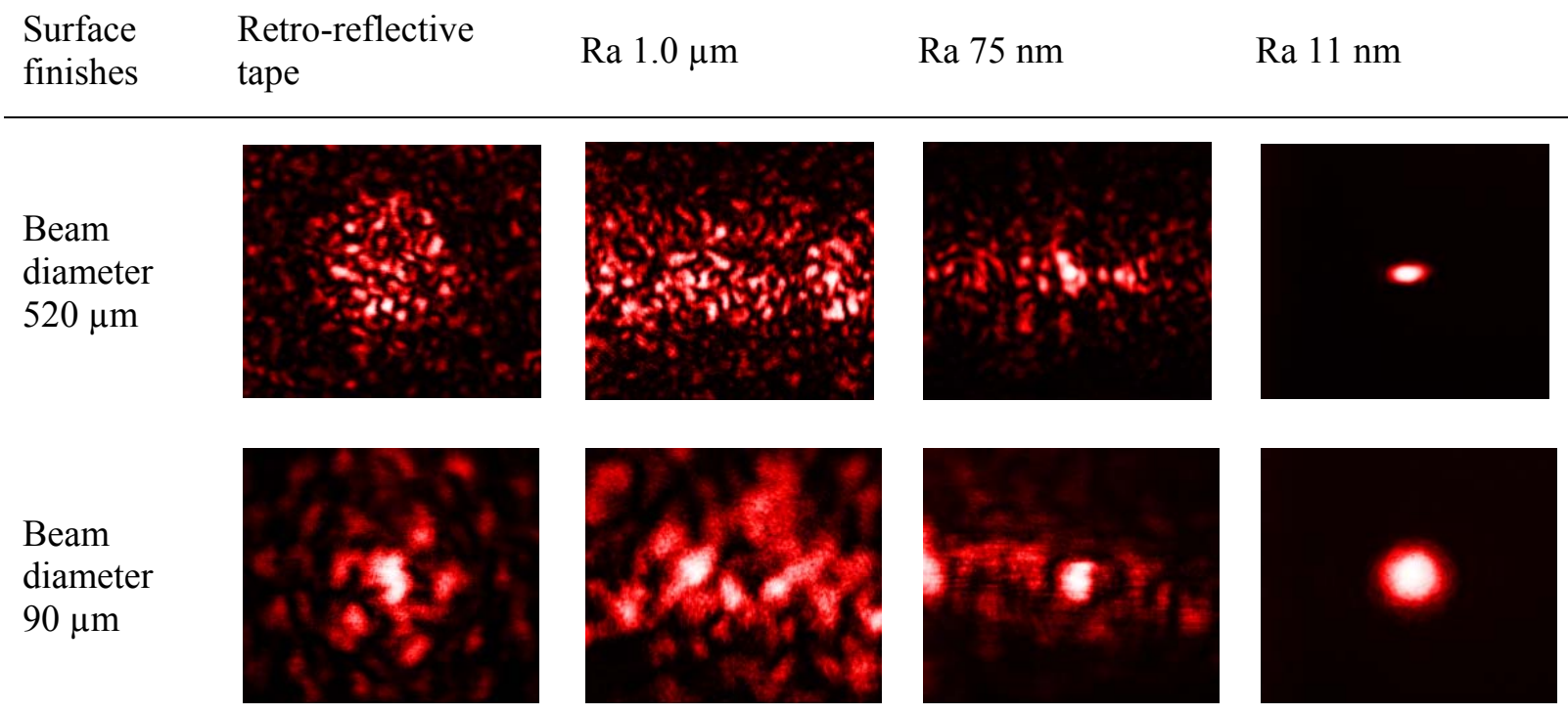

Figure 1. Typical scattered light patterns 


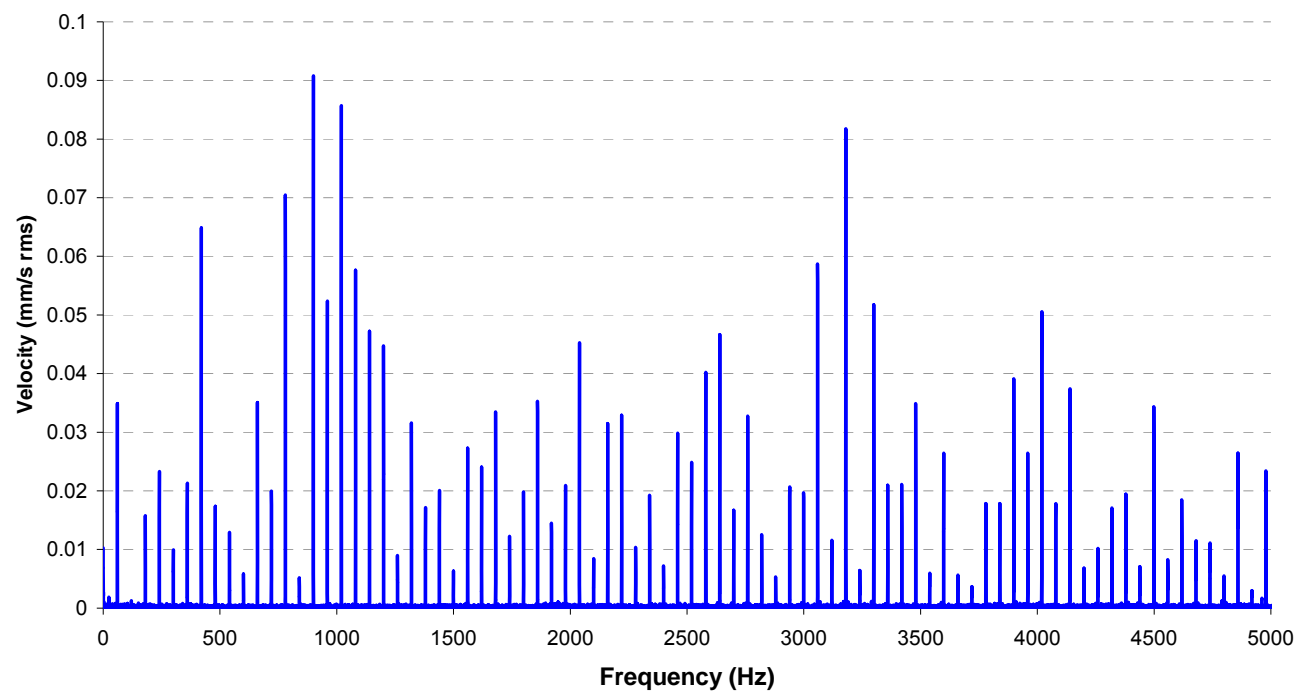

Figure 2. Typical spectrum of apparent velocity dominated by speckle noise. 


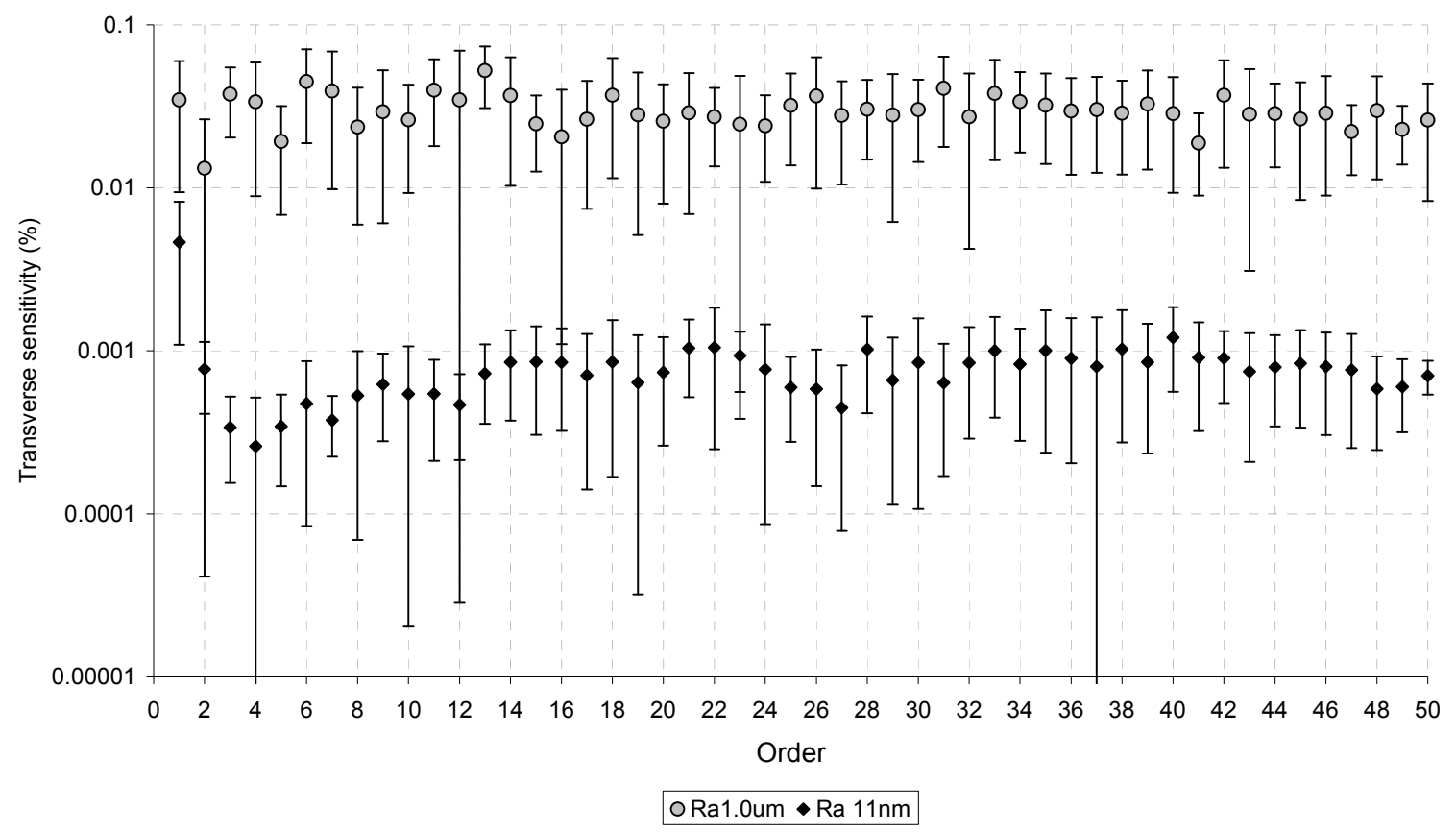

Figure 3. Transverse sensitivity map for Polytec PDV100. Method B. 


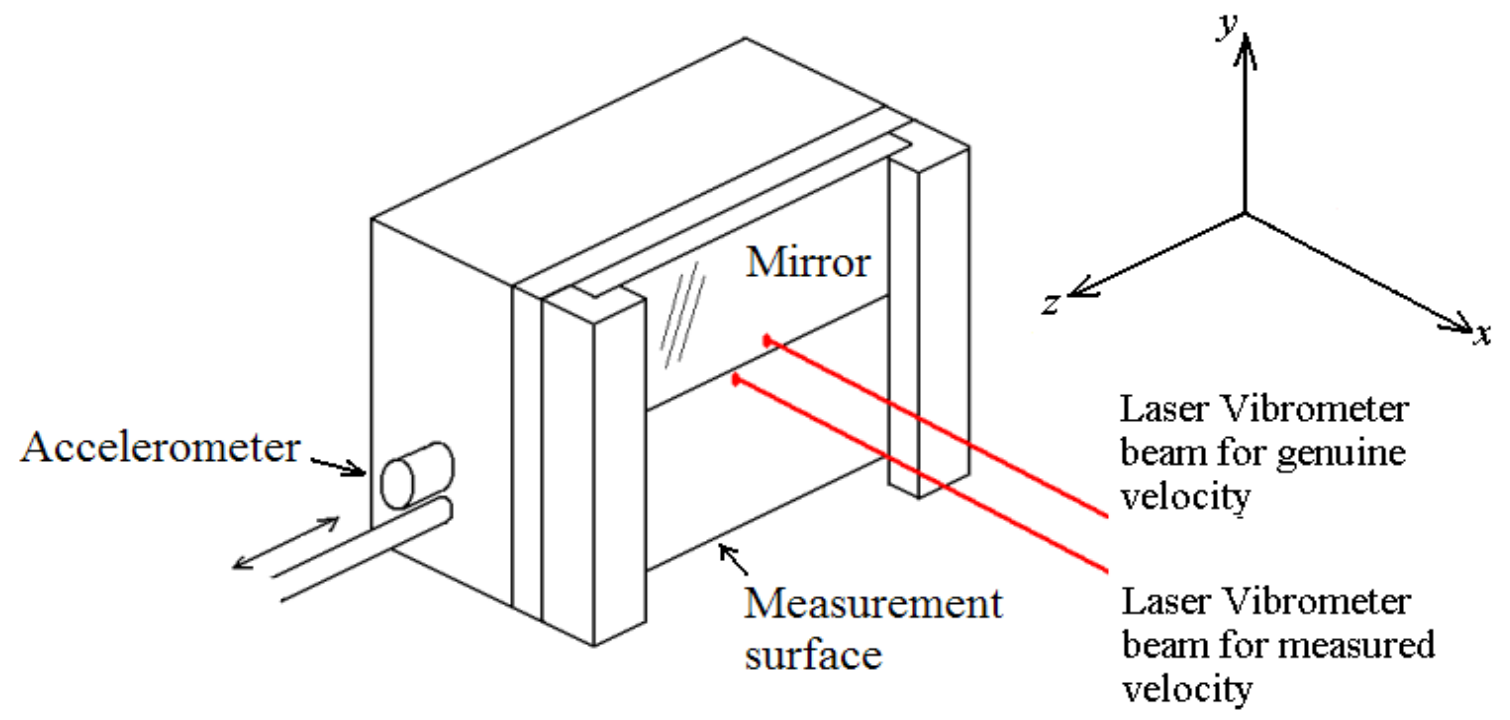

Figure 4. Test set-up for quantification of transverse sensitivity. Method A. 


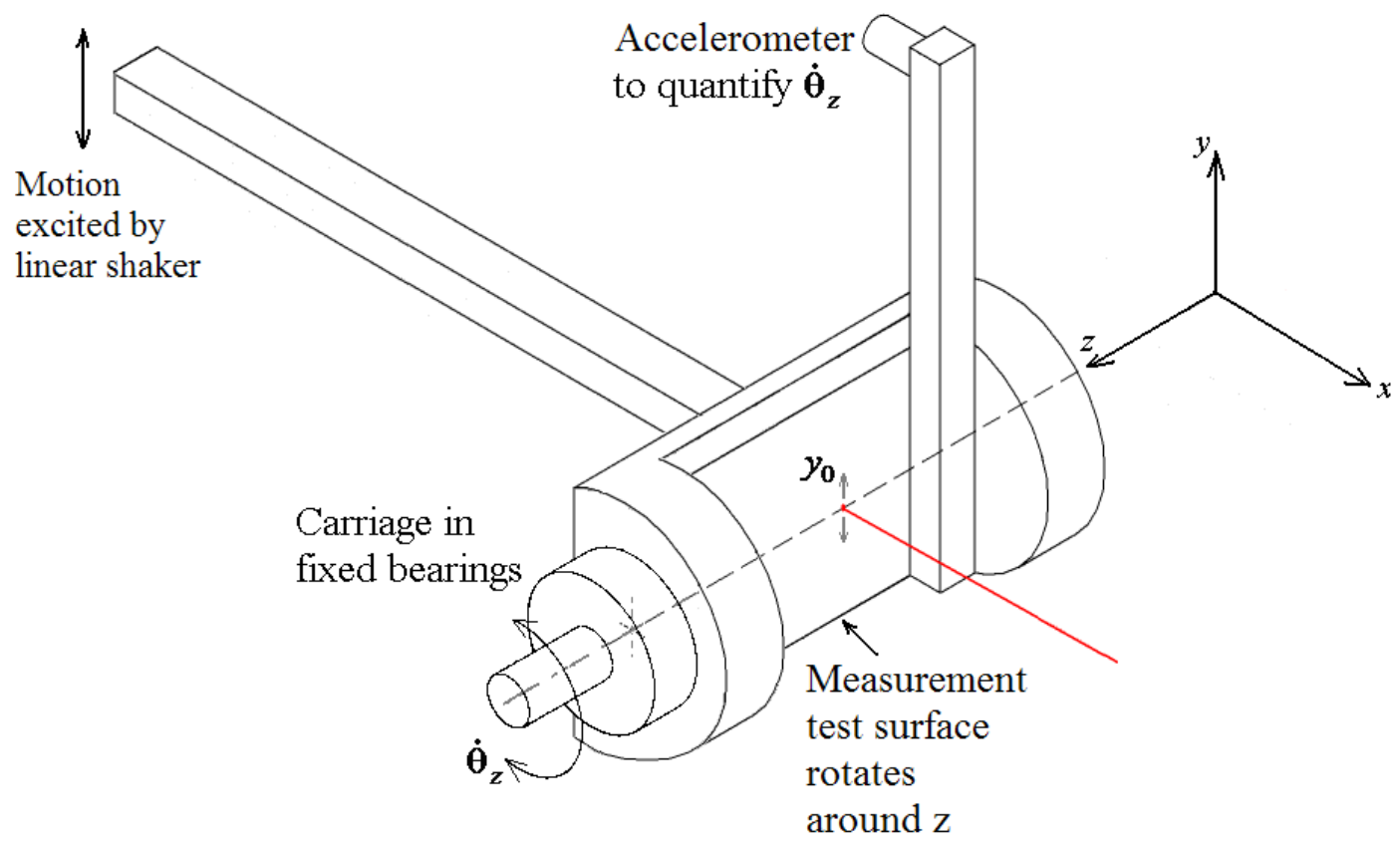

Figure 5. Test set-up for quantification of tilt sensitivity. Method A. 


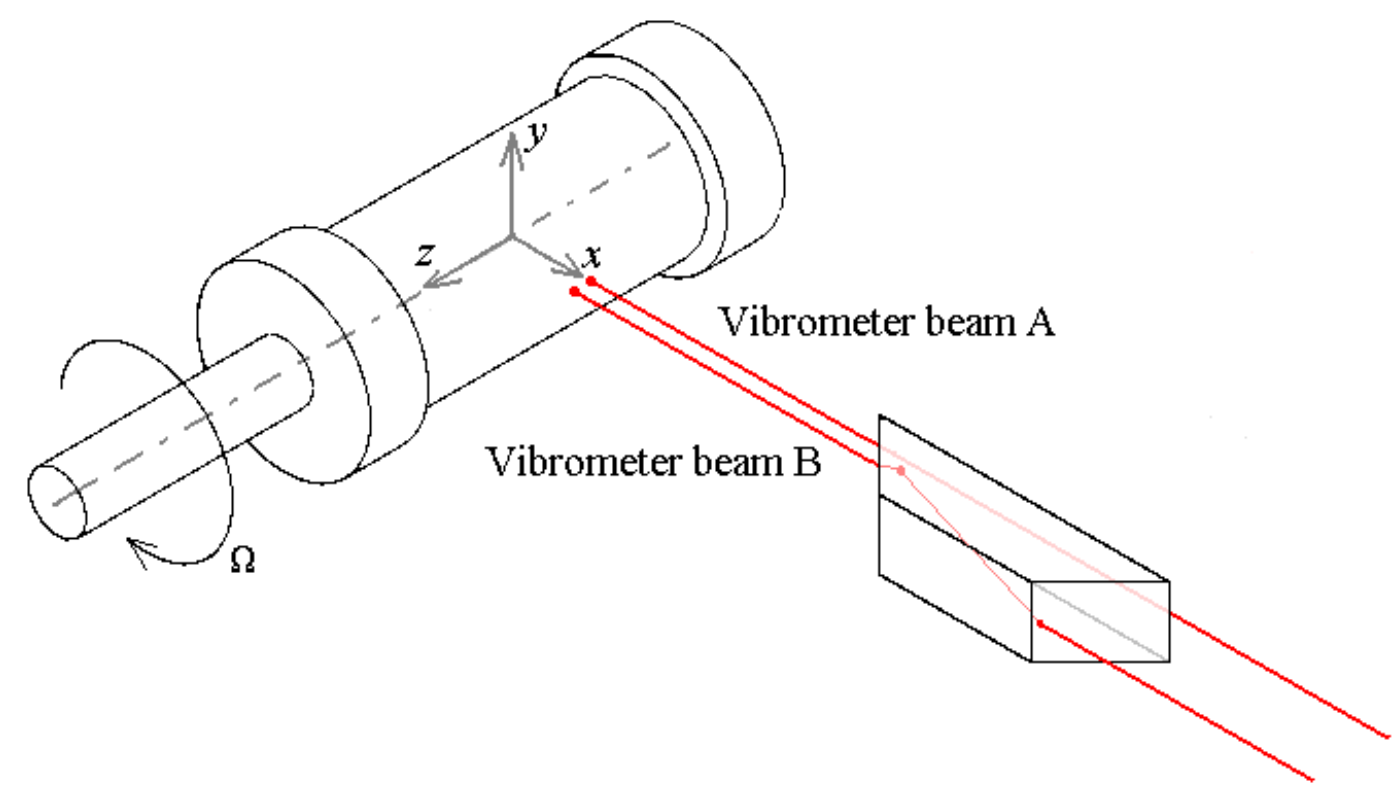

Figure 6. Test set-up for quantification of rotation sensitivity (radial vibration). Method B. 


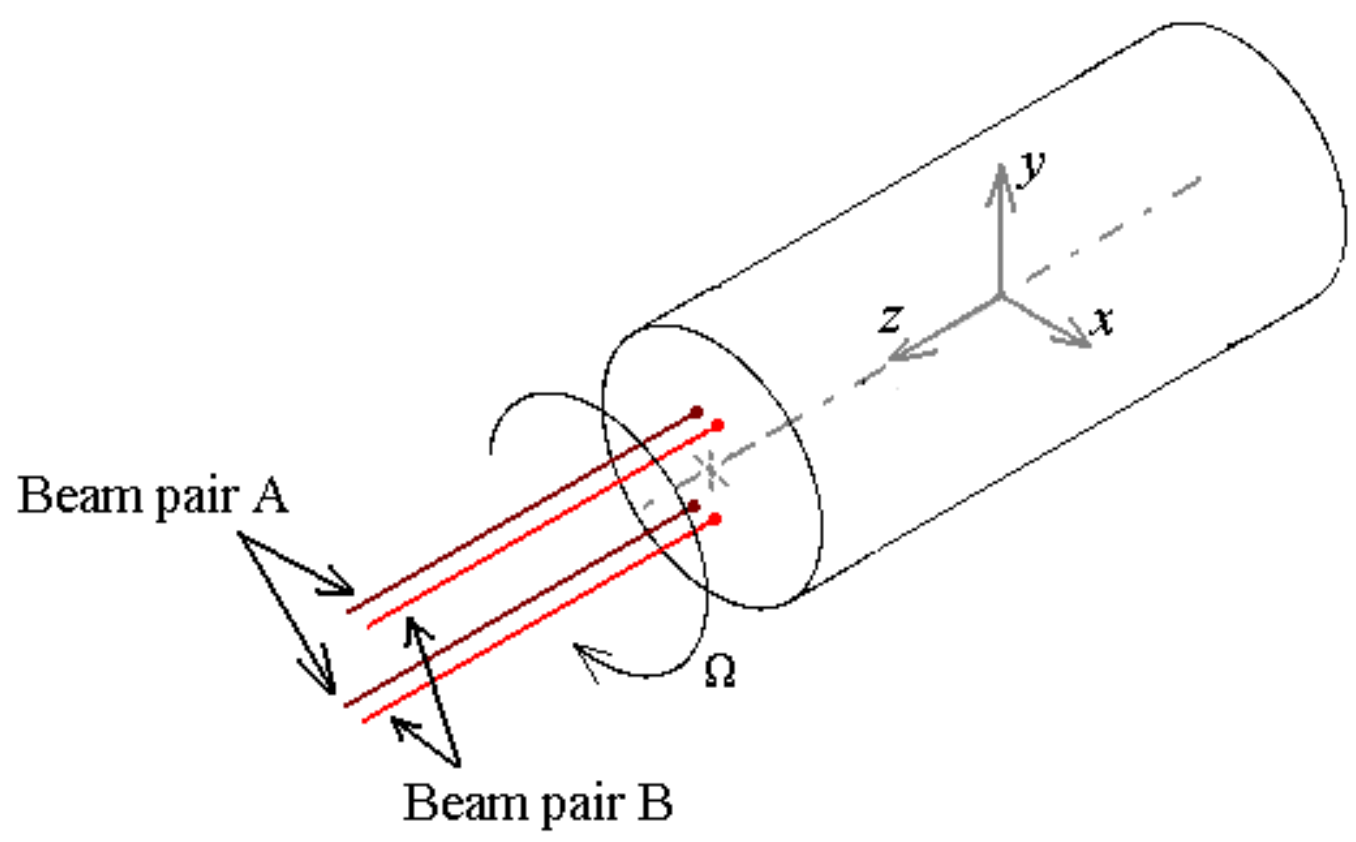

Figure 7. Test set-up for quantification of parallel beam, in-plane rotation sensitivity (pitch / yaw vibration). Method B. 


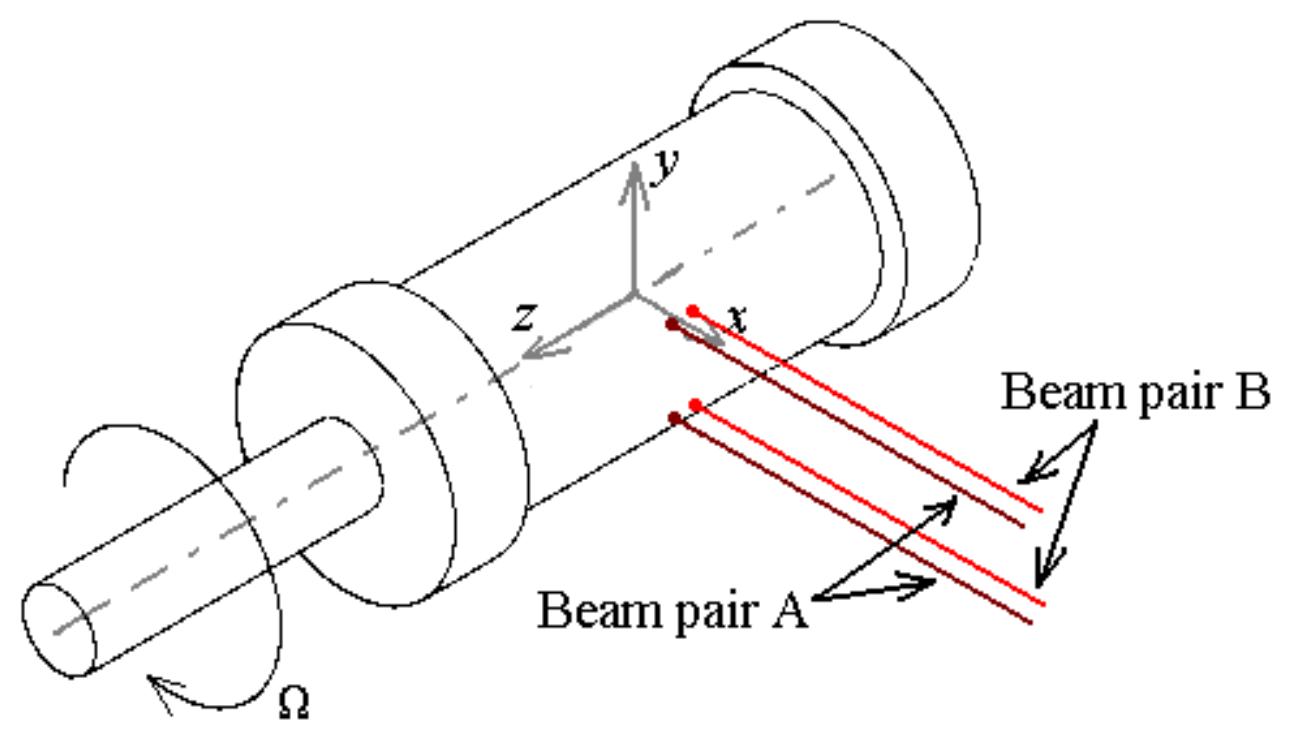

Figure 8. Test set-up for quantification of parallel beam rotation sensitivity (torsional vibration). Method B. 


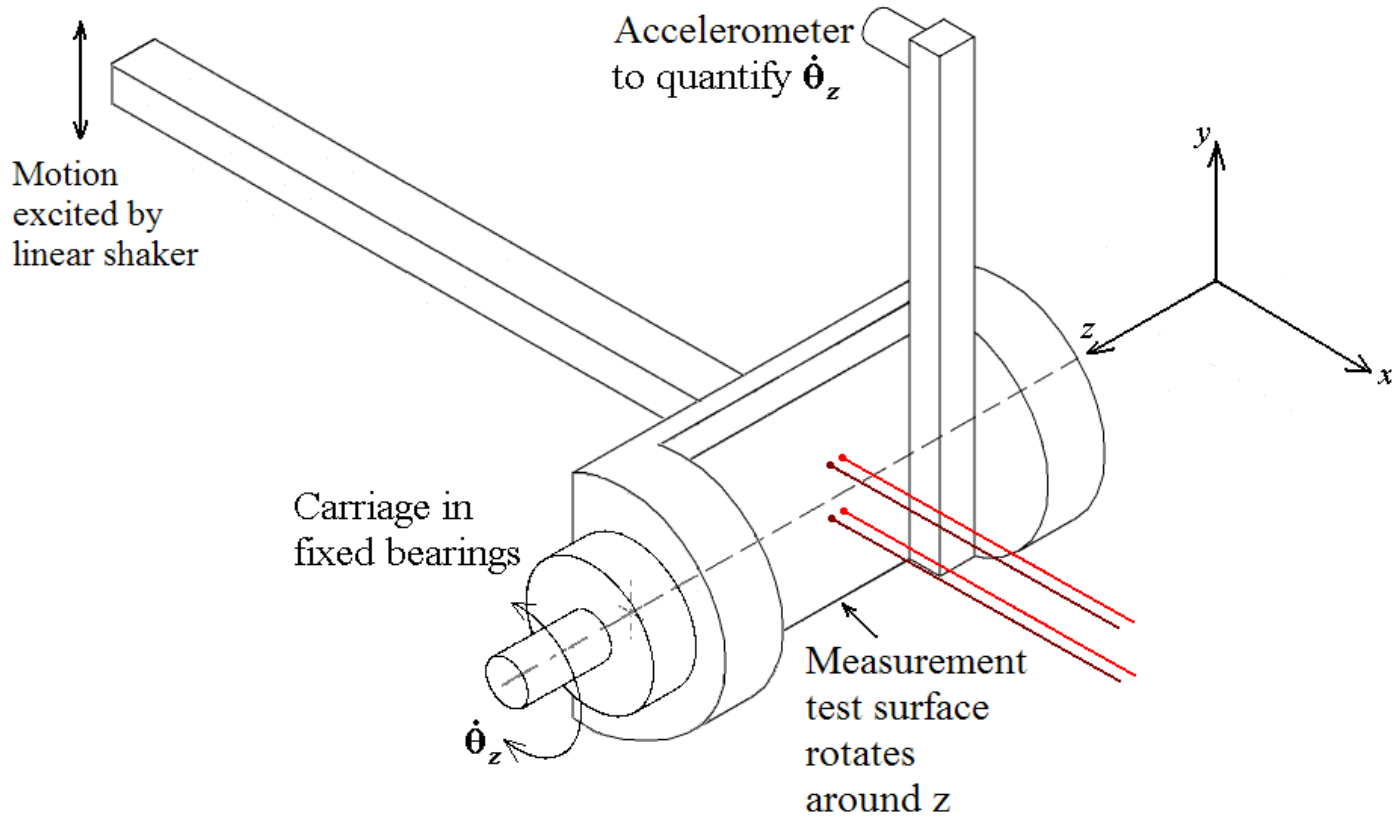

Figure 9. Test set-up for quantification of parallel beam tilt sensitivity. Method B. 


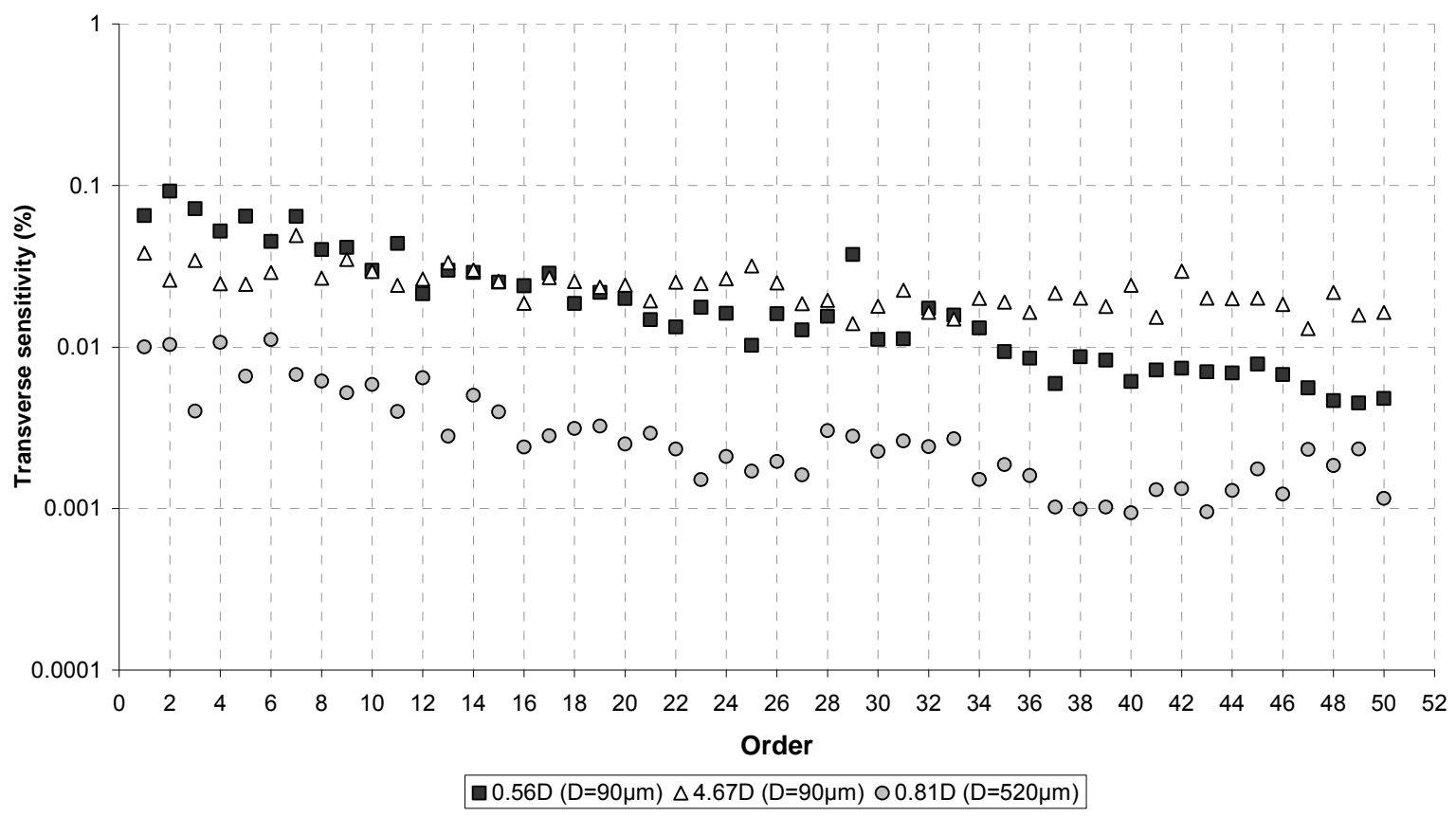

Figure 10. Effect of vibration amplitude on transverse sensitivity. Surface Ra $1.0 \mu \mathrm{m}$ 
Table 1a. Transverse sensitivity (\%) per order: mean (standard deviation) over orders 1-10. Target displacement $420 \mu \mathrm{m}$ rms.

\begin{tabular}{|l|l|l|l|l|l|l|}
\hline & & & \multicolumn{4}{|c|}{ Surfaces } \\
\hline Instrument & $\begin{array}{l}\text { Beam } \\
\text { diameter } \\
\mu \mathrm{m}\end{array}$ & Method & $\begin{array}{l}\text { Retro- } \\
\text { reflective } \\
\text { tape }\end{array}$ & Ra 1 $\mu \mathrm{m}$ & Ra 75 nm & Ra 11 nm \\
\hline Polytec OFV505 & 45 & $\mathrm{~B}$ & $\begin{array}{l}0.0327 \\
(0.0221)\end{array}$ & $\begin{array}{l}0.0402 \\
(0.0250)\end{array}$ & $\begin{array}{l}0.0373 \\
(0.02217)\end{array}$ & $\begin{array}{l}0.00132 \\
(0.000584)\end{array}$ \\
\hline Polytec PDV100 & 60 & $\mathrm{~B}$ & $\begin{array}{l}0.0302 \\
(0.0188)\end{array}$ & $\begin{array}{l}0.0301 \\
(0.0206)\end{array}$ & $\begin{array}{l}0.0289 \\
(0.0202)\end{array}$ & $\begin{array}{l}0.000890 \\
(0.000644)\end{array}$ \\
\hline Polytec OFV302 [5] & 90 & $\mathrm{~A}$ & $\begin{array}{l}0.0245 \\
(0.0175)\end{array}$ & $\begin{array}{l}0.0317 \\
(0.0199)\end{array}$ & $\begin{array}{l}0.0288 \\
(0.0206)\end{array}$ & $\begin{array}{l}0.00730 \\
(0.00258)\end{array}$ \\
\hline $\begin{array}{l}\text { Polytec OFV400 } \\
\text { (single beam mode) [5] }\end{array}$ & 520 & $\mathrm{~A}$ & $\begin{array}{l}0.0112 \\
(0.00704)\end{array}$ & $\begin{array}{l}0.00768 \\
(0.00547)\end{array}$ & $\begin{array}{l}0.0107 \\
(0.00790)\end{array}$ & $\begin{array}{l}0.00895 \\
(0.00808)\end{array}$ \\
\hline
\end{tabular}


Table 1b. Transverse sensitivity (\%): Total rms across orders 1-10. Target displacement $420 \mu \mathrm{m}$ rms.

\begin{tabular}{|l|l|l|l|l|l|l|}
\hline & & & \multicolumn{4}{|c|}{ Surfaces } \\
\hline Instrument & $\begin{array}{l}\text { Beam } \\
\text { diameter } \\
\mu \mathrm{m}\end{array}$ & Method & $\begin{array}{l}\text { Retro- } \\
\text { reflective tape }\end{array}$ & Ra 1 $\mu \mathrm{m}$ & Ra 75 nm & Ra 11 nm \\
\hline Polytec OFV505 & 45 & B & 0.107 & 0.128 & 0.120 & 0.00748 \\
\hline Polytec PDV100 & 60 & B & 0.0989 & 0.0995 & 0.0924 & 0.00487 \\
\hline Polytec OFV302 [5] & 90 & A & 0.0786 & 0.103 & 0.0954 & 0.0407 \\
\hline $\begin{array}{l}\text { Polytec OFV400 } \\
\text { (single beam mode) [5] }\end{array}$ & 520 & A & 0.0388 & 0.0255 & 0.0351 & 0.0327 \\
\hline
\end{tabular}


Table 2a. Tilt sensitivity $\left(\mu \mathrm{m} \mathrm{s}^{-1} / \mathrm{deg} \mathrm{s}^{-1}\right)$ per order: mean (standard deviation) over orders 1-10.

\begin{tabular}{|l|l|l|l|l|l|l|}
\hline & & & \multicolumn{4}{|c|}{ Surfaces } \\
\hline Instrument & $\begin{array}{l}\text { Beam } \\
\text { diameter } \\
\mu \mathrm{m}\end{array}$ & $\begin{array}{l}\text { Method / } \\
\text { angular } \\
\text { disp. }\end{array}$ & $\begin{array}{l}\text { Retro- } \\
\text { reflective } \\
\text { tape }\end{array}$ & Ra 1 $\mu \mathrm{m}$ & Ra 75 nm & Ra 11 nm \\
\hline Polytec OFV505 & 45 & $\begin{array}{l}\mathrm{B} \\
0.5^{\circ} \mathrm{rms}\end{array}$ & $\begin{array}{l}0.0863 \\
(0.0784)\end{array}$ & $\begin{array}{l}0.0813 \\
(0.0532)\end{array}$ & $\begin{array}{l}0.0775 \\
(0.0548)\end{array}$ & $\begin{array}{l}0.0770 \\
(0.0510)\end{array}$ \\
\hline Polytec PDV100 & 60 & $\mathrm{~B}$ & $\begin{array}{l}0.0499 \\
(0.0383)\end{array}$ & $\begin{array}{l}0.0750 \\
(0.0539)\end{array}$ & $\begin{array}{l}0.0574 \\
(0.0391)\end{array}$ & $\begin{array}{l}0.0608 \\
(0.0449)\end{array}$ \\
\hline Polytec OFV302 [5] & 90 & $\begin{array}{l}\mathrm{A} \mathrm{rms} \\
0.78^{\circ} \mathrm{rms}\end{array}$ & $\begin{array}{l}0.0572 \\
(0.0417)\end{array}$ & $\begin{array}{l}0.0783 \\
(0.0643)\end{array}$ & $\begin{array}{l}0.0732 \\
(0.0531)\end{array}$ & $\begin{array}{l}0.0970 \\
(0.0633)\end{array}$ \\
\hline $\begin{array}{l}\text { Polytec OFV400 } \\
\text { (single beam mode) [5] }\end{array}$ & 520 & $\begin{array}{l}\mathrm{A} \\
0.78^{\circ} \mathrm{rms}\end{array}$ & $\begin{array}{l}0.279 \\
(0.153)\end{array}$ & $\begin{array}{l}0.276 \\
(0.158)\end{array}$ & $\begin{array}{l}0.236 \\
(0.166)\end{array}$ & $\begin{array}{l}0.252 \\
(0.168)\end{array}$ \\
\hline
\end{tabular}


Table 2b. Tilt sensitivity ( $\left.\mu \mathrm{m} \mathrm{s}^{-1} / \mathrm{deg} \mathrm{s}^{-1}\right)$ : Total rms over orders 1-10.

\begin{tabular}{|l|l|l|l|l|l|l|}
\hline & & & \multicolumn{4}{|c|}{ Surfaces } \\
\hline Instrument & $\begin{array}{l}\text { Beam } \\
\text { diameter } \\
\mu \mathrm{m}\end{array}$ & $\begin{array}{l}\text { Method / } \\
\text { angular } \\
\text { disp. }\end{array}$ & $\begin{array}{l}\text { Retro- } \\
\text { reflective } \\
\text { tape }\end{array}$ & Ra 1 $\mu \mathrm{m}$ & Ra $75 \mathrm{~nm}$ & Ra 11 nm \\
\hline Polytec OFV505 & 45 & $\begin{array}{l}\mathrm{B} \\
0.5^{\circ} \mathrm{rms}\end{array}$ & 0.285 & 0.267 & 0.253 & 0.257 \\
\hline Polytec PDV100 & 60 & $\begin{array}{l}\mathrm{B} \\
0.5^{\circ} \mathrm{rms}\end{array}$ & 0.166 & 0.256 & 0.190 & 0.203 \\
\hline Polytec OFV302 [5] & 90 & $\begin{array}{l}\text { A } \\
0.78^{\circ} \mathrm{rms}\end{array}$ & 0.219 & 0.278 & 0.239 & 0.318 \\
\hline $\begin{array}{l}\text { Polytec OFV400 } \\
\text { (single beam mode) [5] }\end{array}$ & 520 & $\begin{array}{l}\mathrm{A} \\
0.78^{\circ} \mathrm{rms}\end{array}$ & 0.933 & 0.961 & 0.770 & 0.832 \\
\hline
\end{tabular}


Table 3a. Rotation sensitivity (radial vibration, $\mu \mathrm{m} \mathrm{s}^{-1} / \mathrm{rad} \mathrm{s}^{-1}$ ) per order: mean (standard deviation) over orders 21-30. Shaft diameter $15 \mathrm{~mm}$.

\begin{tabular}{|l|l|l|l|l|l|l|l|}
\hline & & & \multicolumn{5}{|c|}{ Surfaces } \\
\hline Instrument & $\begin{array}{l}\text { Beam } \\
\text { diameter } \\
\mu \mathrm{m}\end{array}$ & Method & $\begin{array}{l}\text { Retro- } \\
\text { reflective } \\
\text { tape }\end{array}$ & $\begin{array}{l}\text { Ra 1 } \\
\mu \mathrm{m}\end{array}$ & $\begin{array}{l}\text { Ra 270 } \\
\mathrm{nm}\end{array}$ & $\begin{array}{l}\text { Ra 65 } \\
\mathrm{nm}\end{array}$ & $\begin{array}{l}\text { Ra 11 } \\
\mathrm{nm}\end{array}$ \\
\hline Polytec OFV505 & 45 & $\mathrm{~B}$ & $\begin{array}{l}0.457 \\
(0.233)\end{array}$ & $\begin{array}{l}0.409 \\
(0.198)\end{array}$ & $\begin{array}{l}0.499 \\
(0.199)\end{array}$ & $\begin{array}{l}0.616 \\
(0.273)\end{array}$ & $\begin{array}{l}0.161 \\
(0.0979)\end{array}$ \\
\hline Polytec PDV100 & 60 & $\mathrm{~B}$ & $\begin{array}{l}0.616 \\
(0.334)\end{array}$ & $\begin{array}{l}0.657 \\
(0.352)\end{array}$ & $\begin{array}{l}0.687 \\
(0.298)\end{array}$ & $\begin{array}{l}0.640 \\
(0.344)\end{array}$ & $\begin{array}{l}0.129 \\
(0.0863)\end{array}$ \\
\hline $\begin{array}{l}\text { Polytec OFV302/323 } \\
{[5]}\end{array}$ & 90 & $\mathrm{~B}$ & $\begin{array}{l}0.530 \\
(0.260)\end{array}$ & $\begin{array}{l}0.664 \\
(0.344)\end{array}$ & $\begin{array}{l}0.674 \\
(0.318)\end{array}$ & $\begin{array}{l}0.535 \\
(0.250)\end{array}$ & $\begin{array}{l}0.144 \\
(0.0741)\end{array}$ \\
\hline $\begin{array}{l}\text { Ometron VH300 } \\
\text { 120 }\end{array}$ & $\mathrm{A}$ & $\begin{array}{l}1.29 \\
(0.703)\end{array}$ & $\begin{array}{l}1.21 \\
(0.763)\end{array}$ & $\begin{array}{l}1.13 \\
(0.583)\end{array}$ & $\begin{array}{l}0.950 \\
(0.511)\end{array}$ & $\begin{array}{l}0.593 \\
(0.261)\end{array}$ \\
\hline $\begin{array}{l}\text { Polytec OFV400 } \\
\text { (single beam mode) } \\
{[5]}\end{array}$ & 520 & $\mathrm{~B}$ & $\begin{array}{l}1.68 \\
(0.923)\end{array}$ & $\begin{array}{l}1.43 \\
(0.883)\end{array}$ & $\begin{array}{l}1.14 \\
(0.516)\end{array}$ & $\begin{array}{l}0.850 \\
(0.603)\end{array}$ & $\begin{array}{l}0.178 \\
(0.112)\end{array}$ \\
\hline
\end{tabular}


Table 3b. Rotation sensitivity (radial vibration, $\mu \mathrm{m} \mathrm{s}^{-1} / \mathrm{rad} \mathrm{s}^{-1}$ ):

Total rms over orders 21-30. Shaft diameter $15 \mathrm{~mm}$.

\begin{tabular}{|l|l|l|l|l|l|l|l|}
\hline & & & \multicolumn{5}{|c|}{ Surfaces } \\
\hline Instrument & $\begin{array}{l}\text { Beam } \\
\text { diameter } \\
\mu \mathrm{m}\end{array}$ & Method & $\begin{array}{l}\text { Retro- } \\
\text { reflective } \\
\text { tape }\end{array}$ & $\begin{array}{l}\text { Ra 1 } \\
\mu \mathrm{m}\end{array}$ & $\begin{array}{l}\text { Ra 270 } \\
\mathrm{nm}\end{array}$ & $\begin{array}{l}\text { Ra 65 } \\
\mathrm{nm}\end{array}$ & $\begin{array}{l}\text { Ra 11 } \\
\mathrm{nm}\end{array}$ \\
\hline Polytec OFV505 & 45 & $\mathrm{~B}$ & 1.46 & 1.30 & 1.59 & 1.96 & 0.509 \\
\hline Polytec PDV100 & 60 & $\mathrm{~B}$ & 1.98 & 2.09 & 2.18 & 2.06 & 0.419 \\
\hline Polytec OFV302/323 [5] & 90 & $\mathrm{~B}$ & 1.70 & 2.13 & 2.15 & 1.73 & 0.459 \\
\hline Ometron VH300 & 120 & $\mathrm{~A}$ & 4.12 & 3.87 & 3.63 & 3.03 & 1.91 \\
\hline $\begin{array}{l}\text { Polytec OFV400 } \\
\text { (single beam mode) [5] }\end{array}$ & 520 & $\mathrm{~B}$ & 5.36 & 4.58 & 3.69 & 2.74 & 0.566 \\
\hline
\end{tabular}


Table 3c. Rotation sensitivity (radial vibration, $\mu \mathrm{m} \mathrm{s}^{-1} / \mathrm{rad} \mathrm{s}^{-1}$ ) per order as a function of shaft diameter and focus location: mean (standard deviation) over orders 21-30.

Surfaces treated with retro-reflective tape. Beam diameter $90 \mu \mathrm{m}$. Method B, Polytec OFV302/323.

\begin{tabular}{|l|l|l|l|l|}
\hline \multicolumn{5}{|c|}{ Shaft Diameter (§ indicates focussed on the rotation axis) } \\
\hline $15 \mathrm{~mm}$ & $40 \mathrm{~mm}$ & $40 \mathrm{~mm} \S$ & $110 \mathrm{~mm}$ & $110 \mathrm{~mm} \S$ \\
\hline $\begin{array}{l}0.530 \\
(0.260)\end{array}$ & 0.756 & 0.508 & 1.28 & 0.718 \\
$(0.339)$
\end{tabular}


Table 4. Parallel beam in-plane rotation sensitivity (pitch / yaw vibration, $\mathrm{mdeg} \mathrm{s}^{-1} / \mathrm{rad} \mathrm{s}^{-1}$ ) over orders 21-30. Shaft diameter $15 \mathrm{~mm}$.

\begin{tabular}{|l|l|l|l|l|l|}
\hline & & & \multicolumn{2}{|c|}{ Surfaces } \\
\hline Instrument & $\begin{array}{l}\text { Beam } \\
\text { diameter } \\
\mu \mathbf{m}\end{array}$ & Method & Quantity & $\begin{array}{l}\text { Retro- } \\
\text { reflective } \\
\text { tape }\end{array}$ & $\begin{array}{l}\text { Smooth white } \\
\text { paint (Hammerite) }\end{array}$ \\
\hline \multirow{2}{*}{$\begin{array}{l}\text { Polytec OFV400 } \\
\text { (parallel beam mode) }\end{array}$} & \multirow{2}{*}{520} & \multirow{2}{*}{$\mathrm{B}$} & Mean & 1.28 & 1.61 \\
\cline { 4 - 6 } & & Standard deviation & 0.627 & 0.795 \\
\cline { 3 - 6 } & & Total rms & 4.08 & 5.16 \\
\hline
\end{tabular}


Table 5. Parallel beam rotation sensitivity (torsional vibration, $\mathrm{mdeg} \mathrm{s}^{-1} / \mathrm{rad} \mathrm{s}^{-1}$ ) over orders 21-30 (over orders 1-10). Surface coated in retro-reflective tape. Shaft diameter $15 \mathrm{~mm}$.

\begin{tabular}{|l|l|l|l|l|l|}
\hline & & & \multicolumn{3}{|c|}{ Quantity } \\
\hline Instrument & $\begin{array}{l}\text { Beam } \\
\text { diameter } \mu \mathbf{m}\end{array}$ & Method & $\begin{array}{l}\text { Mean level } \\
\text { per order }\end{array}$ & $\begin{array}{l}\text { Standard } \\
\text { deviation }\end{array}$ & $\begin{array}{l}\text { Total } \\
\text { rms }\end{array}$ \\
\hline $\begin{array}{l}\text { Polytec OFV400 } \\
\text { (parallel beam mode) [5] }\end{array}$ & 520 & B & $\begin{array}{l}21.5 \\
(16.1)\end{array}$ & $\begin{array}{l}10.0 \\
(8.33)\end{array}$ & $\begin{array}{l}68.7 \\
(51.8)\end{array}$ \\
\hline $\begin{array}{l}\text { Brüel \& Kjær 2523 } \\
(100 \mathrm{~mm} \text { stand-off) }\end{array}$ & 300 & A* & $\begin{array}{l}108 \\
(112)\end{array}$ & $\begin{array}{l}57.5 \\
(47.8)\end{array}$ & $\begin{array}{l}347 \\
(365)\end{array}$ \\
\hline $\begin{array}{l}\text { Brüel \& Kjær 2523 } \\
(200 \mathrm{~mm} \text { stand-off) }\end{array}$ & 360 & A* & $\begin{array}{l}51.9 \\
(65.4)\end{array}$ & $\begin{array}{l}28.8 \\
(29.9)\end{array}$ & $\begin{array}{l}167 \\
(209)\end{array}$ \\
\hline $\begin{array}{l}\text { Brüel \& Kjær 2523 } \\
(300 \mathrm{~mm} \text { stand-off) }\end{array}$ & 425 & A $^{*}$ & $\begin{array}{l}133 \\
(157)\end{array}$ & $\begin{array}{l}66.7 \\
(70.7)\end{array}$ & $\begin{array}{l}425 \\
(498)\end{array}$ \\
\hline $\begin{array}{l}\text { Brüel \& Kjær 2523 } \\
(400 \mathrm{~mm} \text { stand-off) }\end{array}$ & 580 & A* & $\begin{array}{l}202 \\
(260)\end{array}$ & $\begin{array}{l}100 \\
(121)\end{array}$ & $\begin{array}{l}645 \\
(833)\end{array}$ \\
\hline
\end{tabular}


Table 6. Tilt sensitivity (\%) over orders $1-10$. Angular displacement $0.5^{\circ} \mathrm{rms}$.

\begin{tabular}{|l|l|l|l|l|l|l|}
\hline & & & & \multicolumn{3}{|c|}{ Surfaces } \\
\hline Instrument & $\begin{array}{l}\text { Beam } \\
\text { diameter } \\
\mathbf{m}\end{array}$ & Method & Quantity & $\begin{array}{l}\text { Retro- } \\
\text { reflective } \\
\text { tape }\end{array}$ & $\begin{array}{l}\mathrm{Ra} \\
1 \mu \mathrm{m}\end{array}$ & $\begin{array}{l}\mathrm{Ra} \\
11 \mathrm{~nm}\end{array}$ \\
\hline \multirow{2}{*}{$\begin{array}{l}\text { Polytec OFV400 } \\
\text { (parallel beam mode) }\end{array}$} & \multirow{2}{*}{520} & \multirow{3}{*}{$\mathrm{B}$} & Mean & 0.199 & 0.405 & 0.796 \\
\cline { 4 - 7 } & & Standard deviation & 0.106 & 0.235 & 0.685 \\
\cline { 3 - 7 } & & Total rms & 0.705 & 1.51 & 2.56 \\
\hline
\end{tabular}


Table 7. Transverse sensitivity (\%) over orders 1-10 as a function of displacement amplitude.

Beam diameter $90 \mu \mathrm{m}$, surface Ra $1.0 \mu \mathrm{m}$. Polytec OFV302.

\begin{tabular}{|l|l|l|l|l|}
\hline & \multicolumn{4}{|c|}{ Displacement amplitudes } \\
\hline & \multicolumn{1}{|c|}{$420 \mu \mathrm{m} \mathrm{rms}$} & \multicolumn{1}{|c|}{$210 \mu \mathrm{m} \mathrm{rms}$} & \multicolumn{1}{|c|}{$105 \mu \mathrm{m} \mathrm{rms}$} & $52.5 \mu \mathrm{m} \mathrm{rms}$ \\
\hline $\begin{array}{l}\text { Mean level (standard } \\
\text { deviation) by order }\end{array}$ & $\begin{array}{l}0.0317 \\
(0.0199)\end{array}$ & $\begin{array}{l}0.0335 \\
(0.0231)\end{array}$ & $\begin{array}{l}0.0457 \\
(0.0283)\end{array}$ & $\begin{array}{l}0.0567 \\
0.0378)\end{array}$ \\
\hline Total RMS level & 0.103 & 0.108 & 0.150 & 0.188 \\
\hline
\end{tabular}


Appendix A: Manufacturers' recommended stand-off distances used

Polytec OFV505 (single beam): $642 \mathrm{~mm}$

Polytec PDV100 (single beam): $372 \mathrm{~mm}$

Polytec OFV302 (single beam): $600 \mathrm{~mm}$

Polytec OFV323 (single beam): $600 \mathrm{~mm}$

Polytec OFV400 (single beam and parallel beam modes): $400 \mathrm{~mm}$

Ometron VH300 (single beam): $385 \mathrm{~mm}$

Brüel \& Kjær 2523 (parallel beams): $100 \mathrm{~mm}$ to $400 \mathrm{~mm}$ 